(b) Though our modern bards call each of the solstitial quarter days an Alban, there is very little authority for such a use of the name. What appears likely is that Alban became a name of the midsummer festival, and that a bardic scribe at first wrongly applied the name to the other quarter days. The Alban of the bards covered three days, and each day is specially named. The first is the Vigil of the Alban, the second is the Alban itself, and the third is the Banquet of the Alban.

(4) Why have the Welsh made so much of the name Alban? The reason may be found in the association of the name with Caerleon-upon-Usk.

(a) There are some ruins near that ancient city still called Mount St. Alban's.

(b) Mr. Wade-Evans has made out a good case for localising Alban's martyrdom at that spot (in "Archæologia Cambrensis," about two years ago).

(c) Geoffrey of Monmouth tells us of a great observatory or school of astronomers in or near that city.

St. Alban's Day being the chief day of the year, and an observatory bearing his name, probably, at Caerleon being apparently the Greenwich of Wales at one time, it is no wonder that the Welsh bards have adopted the name as a solstitial epithet without ever a mention of Alban's martyrdom.

We have in Wales a very modern instance of the same process. In some districts June 22 is observed as Gwyl Barna, the Vigil of Barnabas. St. Barnabas's Day is the Irth, and in the seventeenth century it coincided with the solstice; but since $175^{2}$ it has been in those parts associated with the 22nd, and Gwyl Barna is now a name of the solstice. In the neighbourhood of Llandeilo Talybont, Glam., it is the custom of the farm labourers to get together the hay-making implements on the morning of Gwyl Barna, before going to a solstitial fair in the neighbourhood.

Llangynwyd, Glam.

The Sun's Motion with respect to the $Æ$ ther.

So far as I know, it has not been pointed out that the velocity of light, as decluced from the observed times of occultation of Jupiter's satellites, is affected to the first order by the motion of the earth and Jupiter with respect to the æther. Taking the times best suited to such observations, when the distance between the two planets is very nearly a maximum or a minimum, there will be no appreciable relative velocity in the line of centres, and, to a first approximation, the velocity with which light from Jupiter approaches us is then made up of the true propagation-velocity increased by the common velocitycomponent of the two planets in the direction earth to Jupiter.

In order to determine the sun's motion with respect to the rther, the values for the apparent velocity of light deducible from the observed times of occultation might be analysed, so as to discover any systematic differences depending on the direction of the line of centres. Only very small corrections would be needed on account of the motion of the planets in their line of centres relatively to the sun. The probable absolute error in the finally deduced velocity of the sun (relatively to the æther) would be of the same order as that affecting the finally deduced velocity of light. The quantity to be determined might perhaps be swamped by the errors of observation, but even so a superior limit could be assigned to the sun's velocity through the æather. Two of the three rectangular components of that velocity being measured in the plane of the ecliptic, the determination of the third component would unfortunately be very badly conditioned. It may be some consolation, howcver, to reflect that a knowledge of our motion with respect to the rether is not theoretically unattainable.

Again, if the mean athereal density is either less or greater where atomic matter is present than in free æther, it appears from some results which I have lately obtained in connection with a modified theory of gravitation that motional forces would be experienced (for example) by two bodies moving with uniform translational velocity through the ather. These forces would be proportional to the product of the masses of the two bodies, to the square of the velocity of translation, and inversely to the fourth power of the distance between the bodies. They would be equal in magnitude and opposite in direction, but would not in general act in the same line, so that an elongated body, partaking of the earth's diurnal and orbital motion, would in general be acted on by a couple. This couple would vary as the diurnal motion changed the orientation of the body, and if the variations were measurably great, we should have the means of determining, save for a constant factor and an ambiguity of sign, the velocity of the earth with respect to the æther at any point of its orbit. Observations at three or more points of the orbit would enable us to evaluate the constant factor and to remove the ambiguity of sign, thus determining the velocity of the sun with respect to the æther.

The effects referred to might or might not be detectable, but by means of quite simple apparatus they could be tested for with great delicacy. I hope shortly to publish a fuller account of the analysis on which the above conclusions are based.

Cambridge, July 29.

C. V. Burton.

\section{The Dog's Sense of Direction of Sound.}

OUR dog, Spot, of the intelligence of which an instance has been recorded in NATURE, is peculiarly sensitive to sound. The following instance may be worth recording. On Sunday, July $2 \mathrm{r}$, a heavy storm of thunder and lightning with rain broke over Wick. I sat in the porch of our house watching-Spot with me. The lightning was frequent, and the thunder played round in all directions--over Bath six miles to the east and Bristol six miles to the south-west.

Spot barked at each clap or rumble and rushed forward, always towards the direction from which the thunder appeared to come; the lightning affected him in no way. It was laughable when the thunder appeared to come from no definite direction, but to play round us. For then he ran, barking, over the lawn and round the trees as if angered by a sound he could not locate. I observed carefully what he did for perhaps half an hour, and I think Spot located the directions of sound at least as quickly as I did myself.

F. C. Constable.

\section{THE INTERNATIONAL CONGRESS ON} SCHOOL HYGIENE.

THE second International Congresy on School Hygiene was opened on Monda last at the University of London by Lord Crewe, in the presence of a large gathering, which included aylegates from all the countries of Europe, the Coplid, and North and South America, in addition to bepresentatives of administrative bodies in Great Britain. We shall publish at a later date an account of the proceedings of the Congress, but are pleased meanwhile to direct attention to the warm interest taken by the King in the objects for the consideration of which the congress was convened; indeed, but for the King's intervention, the congress would probably have been anything but a success, as will be seen by the opening remarks of the president, Sir Lauder Brunton, F.R.S.

Lord Crewe, Lord President of the Council, in opening the congress, said the first duty he had to perform in connection with the opening ceremony wa/ a very agreeable one. He had a gracious commang from the King to express to them the interest with whic. .His. Majesty regarded the subjects with which that ongress was concerned and his hopes that its discussions might be a great success. His Majesty had further commaldey him to express his regret that, owing to his enford absence from London, he was unable to receive those who werc to attend the congress. He was also wivileged as a member of the Government to express the same desire on their part that the proceedings of the congress might be crowried with success, and on behalf of the Government to offer them all a hearty welcome. It was not in a strict sense an official conference. It was not subject to official control, it was not run on official lines, and it was not subsidised by official money. That, from many points of

NO. I97 I, VOL. 76$]$ 